\title{
UN BIEN NATURAL COMPARTIDO
}

\author{
José Corral Lope. Madrid
}

\begin{abstract}
Resumen: Este escrito evalúa con detenimiento las tesis de Orígenes del hombre sobre la eficacia biológica comparándolas con las de la obra Sobrevivir amando.

Palabras clave: eficacia biológica, supervivencia, altruismo.

A shared natural good.

Abstract: This paper carefully evaluates the thesis of Origins of man on biological fitness making a comparison with the others of the book Survival and altruism.

Keywords: biological fitness, survival, altruism.

Recibido: 15 de septiembre de 2019. Aprobado: 15 de noviembre de 2019.
\end{abstract}

\section{Introducción y aviso previo}

Antes del seminario escribí un amplio borrador para la intervención oral. Intervención que luego fue totalmente improvisada. Se supone que ahora debería escribir un artículo "formal" para su publicación. Lo he intentado, pero resulta más aburrido que el primer borrador. Dejo pues el primer borrador levemente corregido. Con el siguiente aviso previo a los lectores:

El libro del profesor Rodríguez Valls intenta, desde su título, resaltar la singularidad del Hombre, de los hombres, frente a los animales. Y para ello describe con mucho rigor lo que los diferencia. Y para resaltar estas diferencias hace también referencia a lo que tienen en común. Pero no desarrolla estos aspectos comunes, que se refieren a la naturaleza, o esencia, de unos y otros: al quiénes somos, al de dónde venimos y al adónde vamos. No comentaré nada sobre estos puntos. Nuestro autor trata amplia y sabiamente las diferencias en estas cuestiones entre el Hombre y los animales. Que son suficientemente significativas como para justificar la singularidad del título.

También trata nuestro autor de otros dos aspectos que parecen más asequibles: los objetivos o fines naturales de hombres y animales y sus comportamientos. Estos aspectos están presentes en todo el texto y el autor también resalta las muchas diferencias que existen entre los fines y los comportamientos de los animales y los del hombre. Y para este resaltar las 
diferencias, en varias ocasiones dice lo común, es decir los fines y los comportamientos que el hombre comparte con los animales y con todos los seres vivos. Pero tampoco se para a mirar estos fines y comportamientos comunes.

Esta actitud de no mirar al fin vital "natural" del Hombre como ser vivo no es exclusiva del profesor Rodríguez Valls. Es común a los filósofos: desde el puro antropomorfismo individualista de Aristóteles, al eudemonismo de Kant y al propio animismo de los animistas que se fijan en la vida de los individuos individuales. Ningún filósofo se ha preocupado de la vida del Hombre con mayúscula, de la continuidad de la especie o familia Hombre, de la posible supervivencia o extinción de la humanidad. Y mucho menos han pensado en lo que deben hacer los hombres, el Hombre, para intentar evitar su extinción. Que yo sepa, solamente Hans Jonas ha intentado apelar a nuestra responsabilidad para cuidar a la especie. Y también los últimos Papas y algunos buenos humanistas estudian y predican nuestra obligación de cuidar la tierra y nuestro hábitat. Pero no conozco ningún filósofo que se haya planteado cuál sea el objetivo vital del Hombre con mayúscula, el sentido "natural" de la vida de nuestra especie.

Los filósofos no se ocupan de "lo material" humano, común con los animales y otros seres vivos. Se han ocupado y ocupan de las diferencias que hacen distintos a los hombres: del espíritu y de sus manifestaciones. Incluso los utilitaristas establecen como bien el bienestar, no la vida. Y no del Hombre, sino de los hombres individuales. Como Kant, ven a la especie y sus grupos como universorum, no como singulorum. Y como Kant, los filósofos han considerado a los hombres como "seres racionales, mortales todos, cuya especie es inmortal". Y de estos seres racionales les interesan las "leyes de la libertad", no las "leyes de la naturaleza". Y así seguimos.

Con este aviso previo, paso a transcribir, levemente actualizado, el borrador preparado para la intervención oral en el seminario. 
Un bien natural compartido

\section{Texto para comentar el libro}

En primer lugar, agradecer a Fernando y al profesor Rodríguez Valls su invitación. Creo que este es mi sexto seminario y en todos ellos he arrimado el áscua a la sardina de mis ideas que, como casi todos saben ya, se resumen en que el Hombre, los hombres, tenemos como deber prioritario el imperativo vital de supervivir amando. (Mi primer seminario fue el 11.6.16 sobre "La conciencia inexplicada" del profesor Arana donde coincidí con nuestro autor de hoy).

En este caso no he tenido que arrimar nada. El libro que comentamos menciona abundantemente mis ideas. En realidad, el "Orígenes del hombre" está lleno de mis ideas. Aunque nuestro autor no las resalta, posiblemente porque no las ve. Las usa sin mirarlas. Como creo que dijo D. Juan Arana, para ver algo hay que mirarlo primero. También lo dice Ortega.

Tengo anotado que Fernando me regaló el libro hace más de dos años, el 27.4.17. Lo leí y subrayé con avidez y seis días después, el 3 de mayo, escribí una nota para mí, donde, entre otras cosas, me dije:

El libro es muy amplio erudito y actual. Y escrito con un estilo claro, fluido y a la vez riguroso. Está tratado con un enfoque científico y multidisciplinar, que es muy de agradecer ya que no es frecuente. Lo he leído y subrayado y he destacado al menos cuarenta y dos páginas donde hay aspectos importantes a comentar referidos a mis ideas.

En todo caso me ha hecho mucha ilusión leer en la pág. 82: “...el ser humano puede encerrarse en su creación y no tener en cuenta ni siquiera su propia supervivencia a largo plazo: su aprecio por la especie y la inclinación natural a que permanezca han desaparecido...

¿Quiere decir el profesor Rodríguez que comparte mi idea de que el ser humano tiene o tuvo una inclinación natural a que la especie sobreviva? ¿ha visto explícita esta idea antes, aparte de en la q. 94 de la Summa de Santo Tomás?

Y luego sigue: 
Cualquier argumento evolucionista incorpora la supervivencia de la especie como fin de la vida”. Aunque la frase no está clara parece querer decir que el fin u objetivo de la vida, entiendo que de la vida humana — la de cada hombre o la de la especie- es la supervivencia de la propia especie humana. Esta idea es mi hipótesis básica pero no he visto que la hayan dicho ni los evolucionistas ni nadie antes que yo.

Y parece que el profesor Rodríguez la da por buena. Pero creo que no se ha dado cuenta de la importancia que esta idea tiene como base de un principio ético universal. Espero que lea mi librito o/y me de oportunidad de comentarlo.

El mismo día 3.5.17 envié por correo un ejemplar de mi Supervivir amando al profesor Rodríguez Valls. Y desde entonces hemos intercambiado por escrito y personalmente algunas ideas, pero seguimos teniendo pendiente llegar a una conclusión común.

Como parte del guion de ese intercambio de ideas a realizar, voy a citar del libro que comentamos, además de los dichos, los párrafos más significativos de algunas de las cuarenta y dos páginas especialmente destacadas.

En la página 103, hablando de la conciencia moral, dice:

...desde los orígenes del hombre se ha producido lo que podríamos llamar una ampliación de la noción de humanidad que eleva la obligación moral no solo a los miembros de la tribu o de la cultura, sino a toda la especie humana [...] Tener a la especie como meta cumple los objetivos biológicos e impone una cooperación social entre los individuos.

En este último párrafo está diciendo otra vez la idea básica. Y en las frases anteriores la historia de intentar cumplir "la obligación moral" que supone. Es decir, la historia del imperativo vital. Pero su interés se centra en qué hacer para cumplir el mandato, no en el hecho de que exista. Y en las coincidencias y diferencias entre los animales y el hombre sobre los comportamientos altruistas y cooperativos para supervivir. Y cita a Darwin y a Frans de Waal para separar la protomoral animal de la moral humana.

Y en la página 128, hablando del cuerpo y de las emociones:

...la emoción nos pone en relación con la supervivencia en las mejores condiciones posibles y acepta el sacrificio en la medida en que sirva para beneficio de los que considera cercanos". Y pone a Hume como ejemplo del emotivismo. Dice: "el cuerpo nos conecta 
Un bien natural compartido

con los valores del yo y del altruismo para la especie. Ahora bien, el emotivismo no puede fundamentar una ética del deber.

También aquí dice la idea básica, pero la dice al pasar porque su interés está en decir la última frase. Y tiene razón: ni la emoción ni el deber que origina son, ni pueden ser, el fundamento de la ética. La emoción y el deber que origina son medios para intentar el objetivo básico. Objetivo que nuestro autor dice y utiliza pero que tampoco aquí se detiene a resaltar. Está a otra cosa. Y también acierta al citar al altruismo, pero no se para a remarcarlo. Todo el largo capítulo 5, págs. 133 a 166, trata de los "Orígenes del intelecto humano". En su primera página dice que esta cuestión:

...es el caballo de batalla de cualquier antropología que busca las diferencias específicas en el ser humano y no solo similitudes con el resto del reino animal”. Está claro que su interés está en buscar las diferencias. Y supongo que por eso da por sabidas y obvias las similitudes.

Y luego dice:

En este ensayo sostengo la tesis de que el intelecto o la conciencia es lo que nos revela una diferencia suficiente y cabal si logramos aclarar en qué consiste y determinar los alcances que procura.

Con este propósito incluye en el capítulo un interesantísimo trabajo sobre: la verdad y la evolución, el instinto animal, la esencia en el hombre, la conciencia, la verdad como posible estrategia de supervivencia, la función de la filosofía en la vida humana, una discusión con Juan Arana sobre la conciencia, la conciencia y la ficción y la visión del tiempo en el hombre. iCasi nada!

He reseñado todos los epígrafes que contiene el capítulo porque todos ellos "traen cuenta" del concepto de "eficacia biológica" que enuncia al principio. Del cual dice que: "Concreta en sí lo esencial de la filosofía evolucionista desde Darwin a Lewontin: adaptación al medio, selección natural y supervivencia del mas apto". Y lo redefine luego, añadiendo el concepto 
de utilidad: "Un ente es biológicamente eficaz cuando logra sobrevivir y transmitir sus genes y no lo es si no lo logra". No queda claro el tipo de ente o entes a que se refiere: organismos, poblaciones, especies, clados, ... ¿'Todos y cada uno?

Y luego su pregunta principal a cuya respuesta dedica el capítulo. Dice: “¿es la verdad importante para la supervivencia biológica? No digo que sea útil, que sin lugar a dudas lo es. Digo si es importante, incluso necesaria, de tal manera que sin ella los seres vivos no podrían conseguir sus propósitos de perpetuarse".

Otra vez en esta última frase enuncia la idea básica: el perpetuarse, la supervivencia, como fundamento de los propósitos de los seres vivos. También aquí la da por sabida. Y yo también. Me interesa ahora responder a su pregunta y resaltar la importancia y la necesidad de "la verdad" en la supervivencia de los seres vivos y en especial en la supervivencia del Hombre.

En los seres vivos "la verdad" que deben saber es la que les dice lo que deben hacer para intentar que su especie sobreviva. En cada momento. Y además ser capaces de hacerlo. Todos quieren hacerlo: por el mandato del imperativo vital implícito en su programación vital. Pero parece que más del noventa por ciento de las especies no han sabido su verdad. O no la han sabido a tiempo. $\mathrm{O}$ no han podido cumplirla. Y se han extinguido.

El Hombre, los hombres, hemos llegado hasta aquí intentando cumplir el propósito de perpetuarnos a través de los grupos, cada vez más grandes, verticales y transversales en que los individuos han convivido: familia, tribu, nación..., agricultores, cazadores, creyentes, filósofos... Es decir, sabiendo y usando las verdades parciales suficientes para conseguir nuestra supervivencia. Pero la verdad o bien universales no estaba ni está explícita. La eficacia biológica definida y dicha por Darwin y Lewontin se refiere a la supervivencia del individuo más apto. Y ese es el bien o verdad que hasta ahora ha sido explicitado. Pero la supervivencia individual es un bien parcial.

Y por ello, esa verdad es insuficiente. Es también una verdad parcial. Y el hombre "cuerpo y espíritu racional" se da cuenta de esta insuficiencia y 
por eso sigue buscando una verdad mayor. Una verdad que tenga como sujeto al Hombre con mayúscula. Además de que los hombres busquen también una Verdad con mayúscula y una vida eterna. Pero esa es otra cuestión que no conviene mezclar para evitar sesgos. Nos quedamos en la verdad vital universal de la ley natural.

Respondiendo de otra forma a la pregunta planteada: seguramente, el Hombre no sobrevivirá si los hombres no descubrimos y explicitamos pronto la verdad vital y la intentamos aplicar. Y ese descubrir y aplicar hemos de hacerlo con las capacidades que nos han traído hasta aquí y que, al menos en calidad y cantidad, nos diferencian de los animales, es decir con nuestras especiales capacidades de pensar, juzgar, decidir. Y de comunicarnos.

$\mathrm{Si}$ se tiene en cuenta estas ideas, creo que todo lo pensado y dicho en el capítulo adquiere un sentido distinto y resuelve las dudas que se plantean en los distintos epígrafes. $\mathrm{O}$ al menos las iluminan. Otro día intentaré esta tarea. Ahora sigo espigando en el rico texto que comentamos.

El capítulo $6^{\circ}$ y último (págs. 167 a 189) trata de la voluntad humana, de la libertad, de la búsqueda del bien, del transhumanismo, de la aldea global. Todo interesantísimo y muy bien tratado y resumido. Solamente cito lo más significativo para nuestras ideas.

Dice en la página 168:

Es el plano de la conciencia moral (el saber aplicado a la práctica) el que debe configurar la estructura de la subjetividad. El problema es que el saber acerca de sí mismo puede que no sea lo suficientemente completo como para obtener una visión moral adecuada de sí y de lo que debe hacer.

Estamos confirmando la necesidad de que: “... tanto la comunidad social como el sujeto", busquen "saber" como guía para el hacer. Pero la verdad de lo que haya que hacer colectiva e individualmente depende de lo que unos y otro consideren "los proyectos vitales ideales", es decir los fines u objetivos: tanto de la comunidad social como del sujeto individual. La vieja e irresuelta cuestión de los fines. Que también delimitan el viejo concepto 
de la libertad humana. Porque es claro que no existe el determinismo para los seres vivos y mucho menos para el hombre.

En la página 176 se plantea más directamente este problema. Dice: "La libertad no es meramente la búsqueda de medios sino determinación de fines, ese es su principal objetivo". Este es un asunto grave. No sé si nuestro autor se da cuenta. El fin del hombre como ser vivo no pudo ni puede ser determinado por el Hombre. Ni por los hombres, individuos o personas. Intentarlo sería el "seréis como dioses". De las varias acepciones de "determinar", los hombres podemos intentar: DRAE: II4. "Señalar o indicar algo con claridad o exactitud", pero no: II3. "Establecer o fijar algo". Este es un error grave de Kant y de los Ilustrados. Creo que por ignorancia más que por soberbia.

Según mi idea, compartida y dicha por el autor, aunque no se haya dado cuenta cabal de ello, el fin vital del Hombre, de los hombres como especie Homo sapiens, es la propia supervivencia. Y este fin está impreso e implícito en la naturaleza de cada hombre y no puede cambiarlo.

El problema es que el fin u objetivo vital prioritario no ha sido aún explicitado y asumido como fundamento ético común. Aunque ha estado y está operativo, en la ley natural, como fundamento implícito de las éticas parciales. Y los hombres y sus diferentes grupos y culturas han vivido, convivido y sobrevivido hasta ahora con fines parciales contingentes. Y con las verdades y las virtudes parciales que han sabido, querido y podido ejercer en cada momento y circunstancia.

Confirmando lo anterior en la página 181 dice: “... se puede establecer que hay un bien natural que el ser humano comparte con los animales y consiste en la realización de actividades que permiten la supervivencia personal y de la especie". En este párrafo está el título de mi comentario.

Nuestro autor vuelve a decir la idea básica, pero con un decir tímido e impreciso. El bien compartido por los animales y por todos los seres vivos es la vida, a intentar conservar mediante la supervivencia de sus especies. El "bien natural compartido" no es "la realización de actividades que permiten la supervivencia personal y de la especie": el bien es la vida. Y para 
intentar conservarla y trasmitirla los seres vivos tienen distintas posibilidades, según sus especies, para intentar conseguir ese objetivo. Y los grados de libertad van desde el mínimo de las bacterias a la enorme libertad de los hombres. Aunque, como dice en la página 169: "El ser humano es libre en la medida en que puede serlo".

Y también coincido en lo que dice en la página 182: “...el medio es a la vez fin en tanto que en su ejercicio se efectúa el fin”. En el caso del Hombre el fin de supervivir casi coincide con el medio: el altruismo/amor. Tanto para la vida en este mundo, como en el otro si existe. Dicho de otra manera: el amor a todos los prójimos, que es el mejor medio para que nuestra especie/humanidad superviva, puede ser, a la vez, fin u objetivo ya que quien ama quiere, prioritariamente, que el objeto de su amor viva siempre. Y feliz. Practicar ese altruismo/amor hace también feliz a quien lo ejerce.

Podría terminar citando a San Agustín y a Teilhard. Pero prefiero citar a nuestro autor, quien, en un texto menos conocido, dice:

He de seguir intentando $[\ldots]$

acelerar un poco más

la llegada del amor entre los hombres.

\section{Epílogo. Que trata de la dignidad humana}

No pensaba escribir nada sobre el epílogo porque las cuestiones que plantea son especialmente difíciles para mí. Pero tengo señaladas algunas frases que, en una nueva lectura, no me resisto a citar y comentar brevemente. Dice en la página 193:

Superior, en el caso de lo humano, no significa ser el tirano del planeta, sino aquel que tiene que administrar los medios teniendo en cuenta el bienestar de todos: la consideración ética correcta es la de la responsabilidad para con el planeta hecha por aquel que, por poder destruirlo, tiene la obligación de salvarlo.

De acuerdo. Pero no es preciso apelar, como Hans Jonas, a la responsabilidad. El Hombre, los hombres, tiene/tenemos la obligación de procurar 
el bienestar de todos y de cuidar el planeta como medios para la propia supervivencia. Por el imperativo vital que llevan implícito y por puro egoísmo.

Y en la misma página: “...hay una universalidad en la dignidad humana plantéese como se plantee esta: toda vida humana posee dignidad por poseer una estructura que la identifica como tal". Y luego: "Un pobre hombre sigue teniendo dignidad, al igual que un criminal, un niño recién nacido o un enfermo."

Aunque no entiendo bien el concepto de "estructura", creo que puedo traducir lo anterior en que todas y cada una de las personas humanas, tienen, por ser humanas, la misma dignidad. Y que también sus vidas sean dignas de respeto. En la página 195 justifica la dignidad con un argumento ontológico y otro ético. El ontológico afirma el carácter de persona de todo sujeto perteneciente a la especie, lo que entraña "dignidad" por el mero hecho de pertenecer a ella. Y el ético mira a la responsabilidad.

Estando totalmente de acuerdo con nuestro autor yo añadiría otros dos argumentos por los que cada persona es "digna" y su vida merecedora de respeto y consideración:

El primero se refiere a que cada persona de nuestra Humanidad, cada individuo humano, cada ser vivo de nuestra especie, es y representa a nuestra humanidad, al Hombre, a nuestra especie. Y lo que alguien hace a otra persona, bueno o malo, se lo hace a la Humanidad, al Hombre, a la especie. Como si se ofende a un policía se ofende a la Policía. O si se roba al cajero de un banco se roba al banco.

Y viceversa: lo que hace cada hombre, lo hace el Hombre. Y este hacer, además de las consecuencias directas que produzca, influye en la moralidad del grupo y por ello de toda la especie, de toda la humanidad. Y la moralidad grupal influye en las éticas implícitas, y en su caso explícitas, del grupo y de la humanidad. Y así hemos llegado hasta aquí. Hasta la ética global existente ahora y en cada momento. De ahí la gravedad del pecado del escándalo. Y la enorme virtud del buen ejemplo.

Lo remacha nuestro autor al final del libro. Dice en la página 196 y última: "El reconocimiento de la común dignidad [...] se convierte en centro 
teórico y práctico de la salvaguarda del mundo: hace pasar del especismo al universalismo ético que lo humano ha hecho entrar en el mundo por primera vez en la historia de la vida."

Por desgracia, "lo humano", los hombres, el Hombre, aún no reconocemos una común dignidad, ni tenemos explicita y operativa una base ética universal. Algunos hombres y algunos colectivos de hombres han asumido y practican éticas parciales que casi coinciden con el principio ético universal implícito. Pero eso, por desgracia, no supone que el mundo "haya entrado ya" en ver ni explicitar una ética universal.

El imperativo vital implícito, la situación y perspectivas del mundo y la globalización han hecho que crezca el sentido de pertenencia a una misma humanidad. Pero seguimos sin tener explicito el objetivo vital común que daría sentido a una base ética universal. A partir de la cual se deberían revisar los valores y virtudes, implícitos y explícitos, de cada grupo o colectivo. Valores y virtudes que pueden ser acertados o erróneos en todo o en parte para cada momento y cada circunstancia.

Esta adopción de fines y valores es lo que se va haciendo cada vez más común debido a la globalización. Pero esta globalización, que facilita el universalismo ético, no garantiza que las éticas parciales universales, tanto teóricas como practicas, sean las buenas. Y si son malas, la universalización las hace más peligrosas. Hasta hace pocos años, los errores o desviaciones grupales, aunque fueran grandes, afectaban al grupo o colectivo que los cometía y en su caso a los contiguos. Ahora, pequeños errores o desviaciones podrían tener, o tal vez ya están teniendo, consecuencias muy graves aplicados universalmente. También se amplifican las virtudes. Pero existe la posibilidad de que las consecuencias acumuladas de los errores sean mayores que los efectos de las virtudes. Sobre todo, porque no se tiene un objetivo vital explícito, común y universal. Y cada grupo busca sus propios objetivos con sus normas morales.

De ahí la importancia y la urgencia de explicitar y asumir lo antes posible una base ética común. Es lo que intentó la Comisión Teológica Internacional. Y la doctrina de la Iglesia, tanto en materia social como 
medioambiental. Pero creo que la base universal, objetivamente válida y aceptable por todos es la que explicita el deber prioritario de todos los seres vivos, incluido el hombre, de procurar la supervivencia de su especie.

Lo dice el libro que comentamos, aunque no la resalte. Supervivencia del hombre, de los hombres, para lo que sea el fin o los fines finales: ser superhombres, ser sabios. O para que reine en todo el mundo el altruismo/ amor como medio/ objetivo para supervivir y ser felices: en esta vida y en la otra si existe. O para intentar realizar el sueño de Teilhard.

\section{Añadidos que confirman lo dicho en el libro que comentamos}

Como digo en la nota del 3.5.2017 citada al principio, me hizo mucha ilusión leer en la página 82 del libro los dos párrafos que, de alguna forma, confirmaban mi idea básica. Después de diecisiete años buscando, era la primera vez que leía algo semejante. Y me surgió la duda sobre si nuestro autor se habría inspirado para ello al escucharme en el seminario del profesor Arana del 11.6.16. Pensé preguntarle, pero nunca lo hice.

Vi luego que también la bióloga Natalia López-Moratalla dice en dos de sus obras que el fin de los animales es la supervivencia de su especie. En "Cuestiones acerca de la evolución humana" de 2008 y en "Inteligencia artificial ¿conciencia artificial?” de 2017.

Ahora, el 27 de mayo del 2019, el profesor Francisco Molina, Coordinador del Grupo de Trabajo Ciencia y Fe del CEU, me recomendó leer " $E I$ azar y la necesidad' de Jacques Monod, premio Nobel en 1965. Libro, editado en 1970, del que yo tenía referencias pero que no había leído pensando que era un trabajo técnico. Lo pedí a Amazon, lo recibí el 28 y leí en la página 26 lo siguiente:

...todo proyecto particular sea cual sea no tiene sentido sino como parte de un proyecto más general. Todas las adaptaciones funcionales de los seres vivos, como también todos los artefactos configurados por ellos, cumplen proyectos particulares que es posible considerar como aspectos o fragmentos de un proyecto primitivo único, que es la conservación y la multiplicación de la especie. 
Un bien natural compartido

Habla luego de la "información teleonómica" como la cantidad de información que debe ser transferida por los individuos a la generación siguiente para asegurar la transmisión del contenido específico de invarianza reproductiva. Y dice luego:

Se verá fácilmente que el cumplimiento del proyecto teleonómico fundamental (es decir la reproducción invariante) pone en marcha, en las diferentes especies y en los diferentes grados de la escala animal, estructuras y performances variadas, más o menos elaboradas y complejas. Es preciso insistir en el hecho de que no se trata sólo de actividades directamente a la reproducción propiamente dicha, sino de todas las que contribuyen, aunque sea muy indirectamente, a la supervivencia y a la multiplicación de la especie.

Monod hace estas afirmaciones como biólogo molecular. Creo que, como Francisco, las considera obvias y sabidas. Pero tampoco deduce de ellas la idea que yo veo y enuncio. Ve las adaptaciones y las actividades que es lo que a él le interesa, y ve la finalidad de esas tareas, pero parece que "no ve" que esas tareas y esa finalidad son las tareas y la finalidad de todos y cada uno de los seres vivos. $\mathrm{Y}$ de sus especies como conjunto de los organismos que las componen en cada momento. Finalidad que dice claramente que es la conservación, multiplicación y supervivencia de las especies.

Confieso que ante esta diferencia de que yo vea en estas frases la que llamo mi idea básica y el que no la vean los autores de las frases me hace dudar de mi hipótesis. Pero por más que le doy vueltas la sigo viendo claramente. Creo que todos la dan por obvia y sabida. Y por ello, aunque la usan como medio para sus trabajos, no se paran a mirarla y por ello no se dan cuenta de que existe y que es la base del comportamiento de todos los seres vivos, incluido el hombre.

La idea es sencilla pero muy amplia y choca con prejuicios y creencias arraigadas. Y presenta dudas técnicas, entre ellas la falacia naturalista, la especie como sujeto, el altruismo como medio... Creo que en mi página Web tengo resueltas todas las dudas que me han planteado. Pero aún así es posible que el equivocado sea yo.

En todo caso, las consecuencias de que mis ideas sean ciertas, y de que si lo fueran se conozcan y asuman, serían vitales (en su doble sentido) para el presente y el futuro del Hombre, de los hombres. Y de su bienestar. Por 
ello pido a quienes lean esto que vean mis hipótesis. Al menos que se paren unos minutos a mirarlas. Y si no las ven, o si las ven y las creen equivocadas o ciertas, me lo digan. Gracias por ello.

Añadido final. Después de escrito lo anterior, acabo de leer "Adaptarse o morir", un ameno libro de divulgación escrito por la joven bióloga Evelyn Segura y editado por Paidos en marzo de 2019. En la Introducción dice al pasar:

Igual que una gacela huye sin pensarlo dos veces ante la presencia de una leona, los humanos también somos seres animales que respondemos de forma instintiva a querer vivir y sobrevivir a nuestras propias amenazas, llegar a la edad reproductiva, crear una nueva generación y perpetuar nuestra especie. En eso se resume todo.

¿Es este el verdadero sentido de nuestra existencia? Podría plantearse como una de las cuestiones filosóficas más importantes de la humanidad, aunque desde el punto de vista biológico, la respuesta asusta por su aparente simplicidad: si.

Creo, efectivamente, que los filósofos pueden decir mucho sobre estas cuestiones.

José Corral

survival@corralforum.org

www.supervivenciayaltruismo.com 